The Geneva Papers on Risk and Insurance, 22 (No. 84, July 1997) 327-335

\title{
Elements of an Effective Workers' Compensation System
}

\author{
by Peter A. Garza-Zavaleta*
}

\section{Introduction}

Today, more than 130 countries have organized workers compensation systems. Certainly Germany, a pioneer in workers' compensation, has legislation which protects workers from the financial consequences of injury in the workplace. In the United States, except for federal government employees and certain marine operations, there is no single workers compensation program. Each of the fifty states has its own system, although they are very similar. In essence, workers' compensation in the United States is a social benefit system in which an employer agrees to pay wage replacement benefits and pay all the medical bills of employees who are injured during the course of their employment, regardless of how the worker's injury was caused. As part of the workers' compensation laws, the employer and employee agree that there will be no lawsuits by the injured employee against the employer, or any of his fellow employees, as a result of a work related injury. The employee agrees that he will only seek workers' compensation benefits which entitle him to medical benefits and weekly wage replacement benefits as opposed to general damages for pain and suffering after a lawsuit. The employer promises to pay those benefits to the employee even if the employees own negligence caused the injury as long as the injury or disease arose out of and in the course of employement.

* Vice President, Liberty International, Boston. This text has been complemented by a document prepared by Liberty Mutual on "Workers Compensations: A Model Approach and a Guide for Policy Development" which can be requested at the Geneva Association. The Liberty Mutual Group is the largest workers' compensation insurer in the United States with an $8.9 \%$ market share and nearly $\$ 3$ billion in written workers' compensation premium and $\$ 6$ billion in property casualty premium. Liberty Mutual was founded in 1911 in Massachusetts with its sole purpose to write workers' compensation for employers in the state of Massachusetts. By 1938 we became the largest workers' compensation insurer in the United States and have maintained that position ever since. 


\section{The social contract}

In the United States the trade off between management and labor is refered to as "the great social contract". In truth, the nature of the social contract began in Germany in the 1870 's and spread to the United States in the early 1900's. In the United States and many other parts of the world, this insurance mechanism has been a private market. It should be emphasized that this workers' compensation system is not intended to be a general health insurance system, a retirement or pension system, or to pay for injuries outside of the work place.

The first principle that must be contained in any workers' compensation system is that employers who reap the economic benefits of the workers labor must be prepared to protect the safety of those workers and pay for any injuries to those workers that arise out of the workplace. This is a fundamental element of any workers' compensation system since both the employer and the injured employee benefit from this arrangement. In an efficient system, businesses experience an increase in productivity since workers return to work faster and the businesses do not have to pay continuing wage replacement benefits. And, because the rules of the game are fairly well understood - what claims are compensable and how much compensation is to paid - the net result is a reduced cost of labor in that segment of the economy covered by workers' compensation.

This was not always the case in the United States. In the early years, the system worked quite well and adhered to its basic objective of meeting both employer and worker needs. However, by the 1980s costs began to escalate out of control. During the decade of the $80 \mathrm{~s}$, wage replacement benefits escalated at the rate of $11 \%$ a year and medical costs grew at a rate of nearly $15 \%$ a year compared to a general inflation rate of only $4 \%$ a year (of course, non-occupational medical costs were rising rapidly during that same period, although not nearly as sharply as workers comp medical). So, until fairly recently the United States was a workers' compensation system with costs growing faster than most every other segment of the economy dominated.

There were three reasons for this rapid rise in costs - which are important to note and to seek to avoid:

The first was a rapid growth in "social inflation" - characterized by over-doctoring, over-lawyering and a pervasive sense of entitlement which led to liberal court decisions and expanded benefits.

The second reason for such rapid growth was a political process that became paralyzed by special interests - lawyers, doctors, labor unions, business groups and insurance companies - each effectively neutralizing the other and the result yielded no legislative solution.

The third reason was an insurance regulatory system with control over only one aspect of the system - insurance rates. Insurance commissioners and their governors were caught in a political vise: insurance companies would file for double digit rate increases, but business could not afford to pay them. The result was that the rate increases had to wait. In effect, the system became underfunded and some insurance companies left the market.

So the all too common scenario in the United States - only a few years ago - was increasing costs, rate inadequacies and legislative paralysis. 


\section{A reform}

By the early 1990 s it all began to change. Why?

For one thing, the insurance industry realized it could not effect change on its own. Although the insurance industry in Germany or elsewhere in Europe may be politically stronger, in the United States a reform movement led by the insurance industry would be doomed to failure. It could act as a convenor or facilitator in a political process... But that requires assembling a critical mass from among the key constituent groups. Not an easy thing to do.

In this regard, Liberty Mutual has played an important role in the reform process in the United States. Because of Liberty's prominent position in the workers' compensation field, the company was able to reach out to leaders of each of the major interest groups - leaders of organized labor, business associations, doctors, lawyers and academics - and search out a common reform agenda.

Surprisingly, there was a lot of common ground: these leaders recognized that there were several basic tenets that ought to guide a process of reforming the workers' compensation system.

They were - and remain:

- System design and governance, including benefit levels, should be left principally to management and labor - the parties to the social compact I spoke of earlier.

- The administrative agency should be well funded, professional and proactive. In the United States it is the public agencies that set standards, monitor system performance and the behavior of employers and various system providers, including insurance companies, and resolve disputes. In the U.S. it is frequently said that a weak agency can ruin a good law; but a good agency can make a bad law work better.

- Reduce litigation - not by attacking the lawyers directly, but by promoting more objective ways to determine the extent and duration of injury, and thus the benefits to be paid.

- Promote medical cost containment through expanded use of managed care. In the U.S., the labor unions will not concede choice of physician to employers, but labor is willing to accept use of managed care arrangements like HMOs and PPOs.

- Commitment to improved workplace safety. Employers and labor unions agree on the objective of workplace safety, but there is less agreement on how to achieve it. Labor wants more regulation; employers want greater flexibility.

Our experience in the United States has been that by reconstructing our workers compensation systems around a few common goals, we have achieved remarkable success both in terms of reducing system costs and in making the system serve its core constituencies more fairly.

The following are a few examples...

a) The reform movement in the United States began in Texas in 1989 with the reform of one of our countries largest workers compensation markets. In the first 18 months after reform, claim costs dropped $38 \%$. The chief feature of reform was reduced litigation through the use of objective impairment ratings and by limiting access to the courts, in favor of agency-based dispute resolutions.

b) The Texas reforms were followed by reforms in Oregon in 1990 . The remarkable thing about the Oregon reforms is how they were achieved. Oregon is a very strong labor state (the logging and paper industries are highly unionized) and, while workers 
compensation costs were acknowledged to be too high and were putting employers at a competitive disadvantage, there was little reason to expect the labor unions to agree to benefit cuts. Instead, the Governor at the time, summoned business and labor leaders to a secret meeting in the basement of the Governor's mansion and convinced them that without reform, jobs would be lost to lower cost states. At one point, it was said that the Governor literally locked the doors to the basement conference room to keep the negotiations moving. The result was a reform law that redistributed - but did not cut - benefits, reduced the role of attorneys in the system by limiting their fees, restricted the use of chiropractors and other palliative care givers, and provided funding for an expanded and more proactive administrative agency. As a result, workers compensation rates have fallen nearly $45 \%$ since 1990 .

c) During the last six years, virtually every one of the 50 states has enacted some reform and more than half have made comprehensive reforms like those in Texas and Oregon. And while the cost ameliorative effect has varied from state to state, in every state the impact on costs can be said to have been substantial - and in nearly every state, both business and labor have benefited.

Certainly, reform has meant different things to different people:

- For workers, it has meant receiving medical treatment from managed care plans, less reliance on lawyers, but no reductions in cash benefits.

- For employers, it has meant cost reductions - leading to lower premiums. And they have not been disappointed.

- For insurance companies, cost reductions are only important if they lead to adequate rates and increased profitability. For the first time in over a decade, workers' compensation is a good line to be writing.

Some service providers, like lawyers, chiropractors, forensic doctors, have seen their incomes from workers' compensation suffer as the reforms have made the systems more self-executing. Others, like safety engineers and managed care providers, have benefited from the reforms as employers seek to reduce costs by eliminating workplace hazards and through greater control over medical costs and return to work planning.

There is no doubt that reform has reshaped the U.S. workers' compensation systems. But as much change as there has been, the fundamentals have not changed.

\section{The workers' compensation system}

The following are ten objectives or critical design elements of an effective workers' compensation system.

\subsection{Management and labor communication}

Management and labor own the system, the legislature should consult with representatives of the workers, for example labor union leaders, and representatives of the business community to reach the legislative and public policy agreement to enact a workers' compensation law. Essentially, these two constituencies should negotiate and come to an understanding of what types of accidents and diseases should be covered under a social contract in the form of workers' compensation and what level of benefit should be paid. This does not mean that the legislature should rubber stamp what business and labor want, but there ought to be a strong presumption in favor of their system design. Obviously the legislature 
will play a large role in defining the public policy surrounding this but the major participants in any system must be heavily involved in the political debate. Insurance companies are a critical resource during this time since they can share their expertise of working in systems in other parts of the world as well as estimating the costs of benefits. Ultimately, there must a fair balance between the cost of the system to the business community and the benefits afforded to the workers.

\subsection{Wage replacement benefits}

Wage replacement benefits do not need to be $100 \%$ of pre-injury wages. Generally, in the U.S., it has been discovered that a wage replacement benefit of about $2 / 3$ of the wages before injury is sufficient to maintain the workers standard of living since the worker typically does not have employment expenses and does not have to pay taxes on benefits. If the worker were to receive $100 \%$ of his pre-injury wage, there would be absolutely no incentive for that worker to obtain proper medical treatment and rehabilitative services to return to work. In addition, significant consideration should be given to a definition of compensable injury. Beyond the initial inquiry of whether the injury is work related is the question of whether the workplace was the sole cause of the injury, the predominant cause or just one of many others causes. For example, is the hearing loss of a 60 year old factory worker caused by the din of the production line or is it a function of the aging process? We have seen a trend in the United States to require more than simple causation, many states now require a showing of principal or predominant cause. The goal is to fairly compensate workers who suffer occupational injury by giving them the security of a portion of their wages on a continuing basis, to pay their fair and reasonable medical bills, and to return them to the workplace as productive workers as soon as possible.

\subsection{Medical care}

The medical benefits should be $100 \%$ of the reasonable medical charges which are necessary to treat and rehabilitate the injured worker. There should be no deductibles or co-pay features which exist in most regular health insurance plans. However, occupational injuries which occur in the workplace are often injuries which can best be treated by occupational medicine specialists, who understand the importance of rapid recovery through aggressive medical intervention, rehabilitation and a prompt return to work. Employers and their insurers should have the right to provide injured workers medical care through a managed care network or a series of clinics controlled by the insurer. This means that before any injury occurs, employers and insurers would identify orthopedic and other specialists who can best treat common occupational injuries such as broken bones and back strains as well as identify the best local hospital emergency rooms to take care of injured workers and the best rehabilitation clinics in an area. Generally insurers and large employers would then negotiate with those doctors and hospitals for discounts on medical services in return for a promise to send all their injured employees to those medical providers. Insurers should constantly monitor those medical providers to make sure that their costs are kept low, that services provided to the workers are of the highest quality, and that the worker returns to work in the shortest possible time. In general terms, this is referred to as the managed care component of a workers compensation system.

In the U.S., over 40 states have adopted some form of managed care, often over the objection of medical providers and organized labor, but the result has been a remarkable reduction in the cost of treating occupational injuries with no lack of medical availability and no relaxation of quality standards. 


\subsection{Rehabilitation services}

A good workers' compensation system should also contain a strong requirement that insurers provide rehabilitation services to injured workers. There is some debate in my country as to whether rehabilitation services should be mandatory. With the goal to return workers to their jobs as quickly as possible, insurers should be mandated to offer physical rehabilitation services. Some workers are injured so badly that they cannot return to their old jobs - for example a construction workers who is paralyzed below the waist from a fall. These workers need occupational rehabilitation and retraining so that they can once again return to work to become productive members of society. At Liberty Mutual Group, we believe that the mandatory offer of rehabilitative services should be balanced with a requirement that once a rehab plan is approved the worker must follow it or suffer a reduction in cash benefits.

\subsection{Legal requirements}

A key component of an effective workers' compensation system is the legal requirement that workers' compensation benefits are the sole remedy for a worker injured on the job, at least against his employer. In the United States this is referred to as the "exclusive remedy doctrine". In short, an injured worker cannot sue his employer and cannot sue any of his fellow employees for on the job injuries because he will be receiving benefits under the no-fault workers' compensation system. Thus, any congestion in the courts because of workers' lawsuits is avoided as is the prolonged uncertainty for workers who would pursue such litigation. In the United States, however, an injured worker can sue an individual or a corporation who is not party to the employment agreement. For example, if a worker were working in an automobile manufacturing plant and was injured by the malfunction of a machine, that worker would also be entitled to sue the manufacturer of the industrial machine for general damages under a theory of product liability. The entire debate about the American legal system promoting such lawsuits is well beyond our discussion of workers' compensation benefits, however, this does provide some idea of the complexities in the system.

\subsection{Classification and rating systems}

A classification and rating system promotes fairness in insurance charges to employers and promotes safety in the workplace for the benefit of workers. The purpose of a classification system is to insure that the premiums charged to a particular business would accurately reflect the risks of injury to workers involved in that particular business. For example, professional workers in an office building have a demonstrably reduced chance of industrial injury compared to construction workers erecting a steel skyscraper. Thus, the insurance rates for workers' compensation charged to employers of office workers should naturally be at a lower rate than that charged for construction workers. In the United States we have a number of national and state rating organizations which gather data on premiums and losses by classification and make that data available to insurers and regulators. This helps to make the system equitable for all employers.

Most insurance rating systems contain a component called "experience rating" or "retrospective rating" which is designed to further differentiate among employers based on their individual safety records. An experience rating system is designed to compare companies in the same classification to each other. For example, one construction company 
building a high rise steel building observes all safety rules. They have nets surrounding the building to prevent falls, a safety committee to look at hazards in the work place and in general seek to prevent injuries, and as a result, have a low incidence of worker injuries. A second construction company which pays no attention whatsoever to workplace safety and has a high rate of industrial injuries should naturally pay a higher insurance rate. Their emerging claims will cost an insurance company a great deal more. An experience rating system examines these trends in a company and penalizes those companies that do not seek to prevent injuries by increasing their insurance premiums compared to other companies in the same risk classification. Again, this is good social policy as well as an incentive for business to invest in safety measures to reduce their accident rates. in the United States both the labor unions and business community actively support the concept of experience rating by insurance companies.

\subsection{Loss prevention engineering}

When an employer purchases insurance from a workers' compensation company, the insurance company, if it is a specialty company, should have a staff of safety engineers who will examine the workplace to identify hazards and likely sources of loss and make suggestions for preventative safety measures. These safety consultants and engineers bring real value to the industrial workplace. The types of expertise can range from ergonomic specialists who can design work areas to avoid repetitive stress injuries; materials handling specialists who will make suggestions about how certain work processes should be performed; industrial hygiene experts who will work with employers on providing better ventilation and air quality to workers to avoid occupational diseases; to driver trainer experts who will work with truck drivers to teach them how to avoid accidents by driving defensively.

By way of note, Liberty Mutual is a leader in workplace safety with over 700 loss prevention engineers in the United States alone, as well as operations in Mexico, Canada and Ireland. In fact, Liberty has introduced "Halo ${ }^{\mathrm{TM}}$ ", a comprehensive worldwide safety services product. The company also operates the Research Center for Health and Safety in Massachusetts, the only one of its kind in the insurance industry which seeks to better understand the causes of workplace injuries and design methods to avoid them.

\subsection{Adminstration}

A well funded, professional, and pro-active government entity to administer the program and resolve any disputes is essential. This agency should be staffed by non-political personnel who can understand the system and fairly administer it for the benefit of both workers and businesses. There are three elements of the administration.

4.8.1. The first element is the supervision of businesses who are subject to the obligation to provide workers' compensation and the insurers who are providing the insurance coverage for the businesses. Workers' compensation should be mandatory for most industrial, mining, manufacturing and commercial businesses. Thus, there must be a system in place to make sure that such businesses have purchased the proper insurance coverage. As part of this insurance relationship there should also be a system in place to insure that the insurance rates or tariffs are fair to all concerned. If the rates are politically suppressed by government regulation then the insurance market will collapse and the system will become bankrupt. There must be sufficient revenue in the system to pay wage loss and medical benefits as well as for the administration of the system while allowing for a fair profit for the insurance 
industry. There is always a temptation in government to suppress insurance rates but our experience in the United States is that rates which are inadequate to fund the losses result in a collapse of the system. This is not a healthy situation for business, the employers, or the economy as a whole.

4.8.2. The second piece of the administration system for workers' compensation is an effective dispute resolution system. There should be an informal dispute resolution system operated by the government and administered locally. Injured workers can then present their case to a neutral government official and business representatives can present their case in a very informal manner without the aid of lawyers. It is not fair for workers, nor appropriate for businesses, to delay the payment of benefits while a prolonged judicial proceeding winds its way through the court system. This administrative agency will also provide support and information to workers so that they can properly present their claims and have them promptly resolved. Workers' compensation is designed to be a no-fault social benefit funded by the private business sector and the insurance companies but administered fairly, quickly and easily by the government. We must remember that good system can be ruined by a poor agency, while a bad system can be improved by a good agency.

4.8.3. The third function of the government agency should be to fairly monitor the financial health or solvency of the private insurers. This should be done through a series of regular reports filed by all insurers utilizing a standard set of forms. There should be a well defined set of acceptable ratios and financial tests that the government publishes so companies will know how their solvency will be judged.

\subsection{Exclusion of lawyers}

It should be mentioned that to the extent we can exclude lawyers for both businesses and workers from an administrative system for workers' compensation, a far better system will exist. Lawyers simply add transaction costs to the system in the form of their fees and these fees are ultimately paid for by businesses which makes the businesses non-competitive in the international marketplace. Recent reforms in the United States have shown that the best way to reduce lawyer involvement is to reduce the need for them. In other words, to reduce disputes, a well staffed, proactive agency can help. But the surest way is to build into a system more objective standards for determining the extent and duration of disability and to provide for independent medical panels to decide disputes over the appropriateness of medical care. Some states have tried to reduce lawyer involvement by regulating their fees. This unnecessarily drags the lawyers into a political dispute and has only short term results.

\section{Conclusion}

So to summarize, there are ten key elements to an effective workers' compensation system.

1. Businesses pays all the costs of the system.

2. Business leaders and labor representatives agree on the basic structure of the system.

3. Wage replacement benefits less than $100 \%$ of wages at time of injury.

4. System provides $100 \%$ medical benefits through managed care. 
5. Mandatory rehabilitation benefits including physical therapy and occupational rehabilitation.

6. Workers' compensation benefits are a worker's exclusive remedy.

7. Insurance classification and rating system that promote fairness and workplace safety.

8. System should encourage loss prevention and safety efforts by employers and insurers.

9. Effective government agency to monitor compliance, solvency, and resolve worker disputes.

10. Keep lawyers out of the Workers' Compensation System.

Liberty Mutual has learned that workers' compensation systems are the result of public policy choices that seek to balance competing interests. In this way, system design is the product of a political process that varies from nation to nation or from state to state and varies over time within each jurisdiction. Hence, it can be said with some certainty, that no existing workers' compensation system is ideal, and all are subject to shifting social, economic and political attitudes.

Thus, for any nation considering the enactment of a workers' compensation program, or considering reform of an existing one, there is no one program that can be copied completely. Fortunately, policy-makers are not without some indicia that can guide them as they choose among different system features. Although the ten principles discussed are a good starting point, the political process will surely produce variations.

Current worker injury compensation systems in western Europe already embrace many of the principles covered here. Certainly, the workers' compensation systems that have emerged in the United States owe their no-fault design to the German system, first envisioned by Bismarck over 100 years ago. These key elements will not guarantee a perfect workers' compensation system, but ignoring these considerations could result in a troubled, unnecessarily expensive and ineffective system. I hope that some of the lessons we have learned in the United States, particularly the lessons of the last few years as we have been able to evoluate the impact of major reforms, can be adapted to European own unique circumstances. The "before and after" analysis of these reforms can proivide-makers with hard evidence of which system features work and which do not. 